DR GREGORE MIELKE (Orcid ID : 0000-0002-3043-2715)

Article type : Original Article

\title{
Participation in sports/recreational activities and incidence of hypertension, diabetes and obesity in adults
}

Gregore I Mielke* 1 - orcid.org/0000-0002-3043-2715 - g.ivenmielke@uq.edu.au

Tom G Bailey ${ }^{1}$ - orcid.org/0000-0001-8531-2780 - tom.bailey@uq.edu.au

Nicola W Burton 2 - http://orcid.org/0000-0002-3221-2265 - n.burton@griffith.edu.au

Wendy J Brown ${ }^{1}$ - orcid.org/0000-0001-9093-4509 - wbrown@uq.edu.au

${ }^{1}$ School of Human Movement and Nutrition Sciences, The University of Queensland, Brisbane, Australia

${ }^{2}$ School of Applied Psychology, Griffith University, Brisbane, Australia

* Corresponding author

Gregore I Mielke

School of Human Movement and Nutrition Sciences (\#26B), Rm 406

The University of Queensland | St Lucia Campus

Brisbane, QLD 4072, Australia

$\mathrm{T}:+6173346-9710$

E-mail: g.ivenmielke@uq.edu.au

Short title: Sports, recreational activities and health

Word count: 3,125

Number of tables: 5

Number of figures: 0

Abstract word count: 233

This article has been accepted for publication and undergone full peer review but has not been through the copyediting, typesetting, pagination and proofreading process, which may lead to differences between this version and the Version of Record. Please cite this article as doi: 10.1111/SMS.13795

This article is protected by copyright. All rights reserved 
Conflict of interest: All authors declare no conflicts of interest.

\section{Abstract}

Evidence of prospective associations between participation in sports and recreational activities (SRAs) and health outcomes at the population level are scarce. We investigated the associations between participation in SRAs and 6-year incidence of hypertension, diabetes and obesity in a cohort of mid-age Australian adults. We analysed data from the HABITAT study $(n=8,784)$, a cohort of adults aged $40+$ years living in Brisbane, Australia. Mail-surveys in 2007, 2009, 2011 and 2013 were used to collect data on participation in 11 SRAs in the past 12 months, as well as self-reported hypertension, diabetes, height and weight. Obesity was defined as BMI $\geq 30.0 \mathrm{Kg} / \mathrm{m}^{2}$. Logistic generalised estimating equations models with a 2-year lag were used. Participation in SRAs in 2007, 2009, and 2011 was matched with outcomes measured in 2009, 2011 and 2013. From 2007 to 2013 the cumulative incidence of hypertension, diabetes and obesity were $14.9 \%, 3.2 \%$, and $11 \%$, respectively. Running, tennis, team sports, exercise classes and resistance training were associated with reduced odds of hypertension. Running, cycling, resistance training and yoga/taichi were associated with reduced odds of diabetes. Cycling, tennis, home-based exercises, resistance training and yoga/taichi were associated with lower odds of obesity. Participation in SRAs was associated with lower incidence of hypertension, diabetes and obesity in mid-age adults over six years. These findings support current efforts to promote wider and continuing participation in SRAs at this life stage.

Keywords: sports; physical activity; cohort studies; ageing; non-communicable diseases; exercise 


\section{Introduction}

The role of physical activity in the prevention and management of non-communicable diseases is well established $^{1}$. However, while there have been several international calls for action to increase physical activity for improved public health ${ }^{2}$, levels of physical activity worldwide remain $\operatorname{low}^{3}$, with associated health-care costs estimated to be more than 53 billion international dollars ${ }^{4}$.

'Exercise' and 'sport' are subsets of physical activity, and it has been suggested that widespread participation could improve population levels of activity and health ${ }^{5}$. The Global Action Plan on Physical Activity 2018-2030, which calls for a 15\% reduction in the global prevalence of physical inactivity in adults and adolescents by 2030, considers the promotion of participation in sports and active recreation across the lifespan an essential strategy for increasing population levels of physical activity ${ }^{2}$. Governments in both the UK and Australia have recently introduced policies which place sport on the health agenda ${ }^{6}$. This recognises the need for national approaches to connect a range of sport and physical activity organisations with other sectors, such as health and education, as well as the need for infrastructure to reduce barriers and enable access to sporting and active recreation facilities.

A recent systematic review identified 22 prospective studies ( 9 cohort and 13 intervention studies) that investigated associations between participation in different sports and health benefits in adults. The authors located studies with 26 specific sports, of which running, football/soccer, gymnastics, recreational cycling and swimming were the most common ${ }^{7}$. They found moderate to strong evidence that running and football were associated with higher fitness and a lower resting heart rate, and that football was also associated with lower adiposity. There was also limited evidence of the benefits of running for metabolic fitness, adiposity and postural balance. Evidence for associations between other sports and health outcomes was mostly inconclusive, due to the paucity of studies and weak study designs ${ }^{7}$. A later study by the same group reported that participation in common types of sports and exercise was associated with favourable health outcomes and reduced risk of mortality ${ }^{8}$, but concluded that the role of recreational activities and sports in reducing the risk of major non-communicable chronic diseases is not yet fully understood. As the risk of the onset of chronic disease increases markedly in mid-age ${ }^{9}$, the aim of this study was to investigate the associations between participation in sports and recreational activities (SRAs) and incidence of hypertension, diabetes and obesity in a cohort of mid-aged Australian adults.

\section{Methods}


We analysed data from the HABITAT study. This is a population-based cohort study of mid-age adults living in Brisbane, Australia. A multi-stage sampling process was used to select a representative sample of over 17,000 adults aged 40-65 years. The baseline measures were collected in 2007 via a mail survey, with 11,085 responses (response rate 68.4\%). The participants were surveyed by mail again in 2009, 2011 and 2013. At all surveys, participants provided sociodemographic, behavioural and health information. Participants provided consent forms and the study protocols received ethical clearance from the Queensland University of Technology Human Research Ethics Committee (Ref. Nos. 3967H \& 1300000161). Detailed protocol and further details of sample selection, methods and measurements have been published elsewhere ${ }^{10}$.

\section{Participation in sports and recreational activities}

In 2007, 2009 and 2011, participants reported frequency of participation in each of 11 SRAs (running, cycling, swimming, golf, lawn bowls, tennis, team sports, home-based exercises, exercise classes, resistance training, and yoga/Pilates/t'ai chi/qigong (subsequently referred to as 'yoga/taichi') in the last 12 months, with response options of: a) never; b) once every six months; c) once a month; d) once every two weeks; e) once a week; f) more than once a week. For the present analyses, we grouped responses into three categories: never (a); some participation (b, c or d); or at least once a week (e or f).

\section{Hypertension, diabetes and obesity}

Participants reported height and weight, and whether or not they had any specified long term conditions at all surveys. Hypertension and diabetes were defined as a positive answer to the following question: "Have you ever been told by a doctor or nurse that you have any of ..." followed by hypertension and diabetes. Participants were asked to indicate "yes" to those conditions that "have lasted, or are likely to last, for 6 months or more". Body Mass Index (BMI) was calculated as weight $(\mathrm{Kg}) /$ height $^{2}$, and obesity was defined as $\mathrm{BMI} \geq 30.0 \mathrm{Kg} / \mathrm{m}^{2}$.

\section{Covariates}

Potential confounding variables considered for these analyses were collected at baseline; they included gender, age, education level, annual income, living arrangements, cigarette smoking status and total physical activity in MET.minutes per week. In each survey physical activity was assessed using the Active 
Australia Survey, which measures frequency and total duration of walking (for exercise/recreation or to get to and from places), moderate intensity and vigorous physical activities in the last week. The Activity Australia Survey is used for surveillance of physical activity in Australia and has acceptable levels of reliability and validity ${ }^{11}$. The weekly volume of physical activity in MET.minutes for each participants was calculated by the sum of times spent walking and in moderate physical activities (weighted by a MET value of 3.33), and the time in vigorous physical activities (weighted by a MET value of 6.66). Participant levels of physical activity were categorized as none ( $<33$ MET.min/week), low (33 to 499 MET.min/week), moderate (500 to 1999 MET.min/week) or high ( $\geq 2000$ MET.min/week). The current Australian recommendation for physical activity is equivalent to $\geq 500 \mathrm{MET}$.minutes/week. ${ }^{12}$

\section{Statistical analysis}

Baseline characteristics were summarized by gender and age groups. Logistic Generalized Estimating Equation (GEE) models with a 2-year lag were used to assess the longitudinal associations between participation in SRAs with hypertension, diabetes and obesity. GEE models were used because they account for the clustering of repeat measures within individuals and for missing data, with the assumption that data are missing at random. SRAs in the past 12 months at surveys 1-3 (2007, 2009, 2011) were matched with outcomes measured at surveys 2-4 (2009, 2011 and 2013) respectively. For this study, only participants who returned a completed survey at baseline and responded to at least one of the subsequent surveys were analysed $(n=8,784)$. Data from participants who reported the health condition at survey 1 (baseline) were excluded from the analyses for that outcome (1,888 for hypertension; 439 for diabetes, and 1,853 for obesity), so that incidence over the following six years could be studied. Analyses were conducted using two different models, with "never" used as the reference category: Model 1 included gender, age, education level and cigarette smoking status. Model 2 included all variables from Model 1 plus total weekly volume of physical activity. All analyses were conducted in Stata 16.0.

\section{Results}

From the 11,035 participants who returned a completed survey at baseline, $79.6 \%(n=8,784)$ responded to at least one of the subsequent surveys, $64.3 \%(n=7,098)$ responded to all three following surveys and $49 \%$ $(n=5,404)$ completed all four surveys; Sociodemographic characteristics of the analytical sample $(n=8,784)$ at baseline are presented in Table 1. There were no remarkable differences between the original and analytical samples (Supplementary Table 1). At baseline, the prevalence of hypertension was $21.5 \%$ (95\%CI: 20.6-22.4), of diabetes was 5\% (95\%CI: 4.6-5.5) and of obesity was $21.1 \%$ (95\%CI: 20.2-22.0). 
These estimates varied by sociodemographic and health variables; prevalence tended to be higher in men, older age, individuals with lower education level and those with low physical activity levels (Table 1). Over a 6-year period the cumulative incidence of hypertension was 14.9\% (95\% CI: 13.9-15.9), of diabetes was 3.2\% (95\%CI: 2.8-3.7), and of obesity was 11\% (95\%CI: 10.1-11.9). (Supplementary Figure 1).

\section{$<<$ INSERT TABLE 1>>}

The description of SRAs by gender and age is presented in Table 2. Overall, home-based exercises, resistance training, running, cycling and swimming were the most commonly reported weekly activities, with slight differences between men and women. Frequencies were higher among men than women for running, cycling, playing golf and team sports, and higher in women than men for home-based exercises, exercise classes, swimming and yoga/taichi. The percentage of participants who reported at least weekly running, cycling, swimming, participation in team sports and resistance training decreased with age, while participation in golf and lawn bowls increased with age.

\section{$<<$ INSERT TABLE 2>>}

Levels of physical activity in MET.minutes per week, by frequency of participation in SRAs are presented in the Supplementary Figure 2. Overall, those who reported participation in SRAs were more likely to meet current recommendations for physical activity ( $\geq 500$ MET.minutes/week), than those who did not. Among those who reported never participating in sports and recreation activities (top panel of Supplementary Figure 2), the proportions of participants who were categorised as not meeting the current recommendation for physical activity ranged from $40.8 \%$ for lawn bowls to $48.5 \%$ for resistance training. Among those who reported at least weekly participation in SRAs, golfers were the most physically active group; only $7 \%$ did not meet current PA guidelines. In contrast, one quarter of those who reported doing home-based exercises at least weekly did not achieve the current physical activity recommendations.

Associations between participation in recreational activities and incident hypertension are presented in Table 3. Before adjustment for physical activity levels, participation at least weekly in any of running, tennis, team sports, exercise classes and resistance training was associated with reduced odds of incident hypertension. When analyses were adjusted for total physical activity levels, the magnitude of associations were slightly attenuated; only running and resistance training at least once a week were associated with reduced odds of incident hypertension.

$<<$ INSERT TABLE 3>>

This article is protected by copyright. All rights reserved 
Running, cycling, resistance training and yoga/taichi were associated with reduced odds of incident diabetes. After adjustment for total physical activity level, only cycling and resistance training were associated with lower risk of incident diabetes (Table 4).

\section{$<<$ INSERT TABLE 4>>}

Associations between participation in SRAs and incident obesity are presented in Table 5. Cycling, tennis, home-based exercises, resistance training and yoga/taichi at least weekly were associated with lower odds of incident obesity. After adjustment for total physical activity levels, these risk reductions were unchanged.

\section{$<<$ INSERT TABLE 5>>}

Sensitivity analyses were conducted including 1) only participants who responded all surveys; and 2) individuals who did not have any of the three conditions at baseline. Overall, the magnitude of associations did not change, but confidence intervals became wider. When only data from complete cases (those who responded all surveys) were analysed, running was associated with reduced risk of incident hypertension and obesity, and cycling and resistance training were associated with lower risk of incident diabetes (Supplementary Tables 2-4). The effects of adding the other two health conditions, and participation in other SRAs as covariates are shown in a Supplementary Tables 5-7.

\section{Discussion}

This is one of the first prospective studies to demonstrate associations between participation in SRAs in mid-life and the development of hypertension, diabetes and obesity, which are major health conditions. In this large population-based cohort of mid-age Australian adults, as least weekly frequency of running, tennis, team sports, exercise classes and resistance training were each associated with lower incidence of hypertension. Running, cycling, resistance training and yoga/taichi were each associated with reduced risk of incident diabetes, and cycling, tennis, home-based exercises, resistance training and yoga/taichi were each associated with lower risk of incident obesity. Participation in swimming, golf and lawn bowls was not associated with any of the outcomes.

Home-based exercises, resistance training and running were the three most common SRAs in this cohort. This is consistent with other Australian research identifying running/jogging, fitness/gym activities, swimming and golf as common SRAs among older adults ${ }^{13-15}$. Our previous HABITAT research indicated preferences for activities that can be done alone, close to home, and with little or no $\operatorname{cost}^{16}$, and not group- 
based, supervised, or team-based activities. Other researchers have also reported preferences for exercising alone and enjoyment of unstructured activity ${ }^{17}$ at this life stage.

In the current study we also noted variations in activities by gender and age. Consistent with other research ${ }^{22-24}$, running and cycling were more frequent among men and exercise classes and yoga/taichi were more frequent among women. Previous research with this cohort has shown that women are less likely to prefer activities that are competitive, vigorous, and done outdoors ${ }^{18}$.

Notably, most types of SRA were less frequent among older participants, with the exception of golf and lawn bowls. Again, this is consistent with our previous work which indicates that older people prefer moderate intensity activities performed with people of the same age ${ }^{16}$. Given the established health benefits of moderate intensity physical activity, more work is needed to identify strategies to enhance active recreation among those aged $60+$ years ${ }^{19}$.

Over six years the cumulative incidence of hypertension was $15 \%$, of diabetes was $3 \%$ and of obesity was $11 \%$. With a population estimate of nearly 650,000 adults aged 40-65 living in Brisbane in $2011^{20}$, these estimates would translate to approximately 96,000 new cases of hypertension, 21,000 new cases of diabetes and 71,000 new cases of obesity in the local population. Extrapolating to the Australian population, this would mean more than 2 Million new cases of people living with these health conditions, which would incur significant health costs. Spending on health increased from an average of AU\$ 5,500 per person in 2006/2007 to AU\$ 7,100 per person in 2015/2016 ${ }^{21}$, and in 2015/2016, >15 Million prescriptions for hypertension and diabetes medications were dispensed ${ }^{21}$.

Running has been shown to reduce health risks in $\operatorname{most}^{22,23}$, but not all ${ }^{8}$, large scale population cohort studies. In a recent systematic review, running for as little as 5-10 $\mathrm{min} /$ day was associated with reduced risk of overall and cardiovascular mortality ${ }^{24}$, and improved aerobic fitness ${ }^{7}$. In the current study, we observed that running at least once a week was associated with reduced risk of developing hypertension and diabetes, but not obesity. However, in a cohort of mid-age adults in the US, jogging was associated with attenuation of weight gain over 10 years after the age of $45 y,{ }^{24}$ which implies that running has a role in weight gain prevention. Recreational cycling at least once a week was associated with reduced risk of incident diabetes and obesity. This is also consistent with previous studies ${ }^{7,8,25,26}$. For example, Littman and colleagues have shown reduced weight gain in mid-age US adults who reported fast cycling 25 , and a systematic review and 
meta-analysis found a $10 \%$ reduction in risk of all-cause mortality with 11.25 MET.hours (675 MET.mins) per week of cycling ${ }^{26}$.

A recent scoping review of the relationships between golf and health suggested that golf can provide moderate intensity physical activity, which should result in improved cardiovascular and metabolic health. ${ }^{27}$ In our HABITAT cohort, adults who reported participation in golf were the most active group according to the Active Australia Survey, but they did not have reduced risk of incident hypertension, diabetes or obesity. This might be because recreational golfers walk at a low intensity, or because many opted to use a golf cart instead of walking the course ${ }^{28}$. More studies are needed to better understand the relationships between golf and health outcomes. For example, 20-weeks of golf in previously inactive midaged adults showed no benefit on blood pressure, but did show benefits for weight reduction ${ }^{29}$.

In this study we were not able to assess the dose-response association between participation in SRAs with incident hypertension, diabetes and obesity, because participants were only asked to report frequency of participation. Our findings that even some participation was associated with reduced risk of incident chronic conditions illustrates the non-linear relationship between physical activity and health outcomes. Numerous studies have shown that the greatest risk reductions are observed when physical activity increases from 'none' to 'some' ${ }^{30}$. As we did not ask about history of participation, we cannot say whether our findings reflect a long history of activity, or whether increasing activity in mid-life is beneficial. Others have suggested that it is not too late to start increasing physical activity in mid-life for health benefits ${ }^{31}$.

The main strengths of the present study are that we conducted prospective analyses of associations between participation in SRAs and three important health conditions, using data from a large population-based cohort of mid age Australian adults. This is one of the first studies to investigate these associations in such a large, population representative sample, and to show that a range of different SRAs could be important for reducing risks of hypertension, diabetes and obesity, regardless of total physical activity levels. Our results show that resistance training may be important for the prevention of all three conditions. Given the repeated assessment nature of this study, we could account for within person changes in participation and occurrence of disease over time.

Some limitations should also be acknowledged. Both the main exposure measure (frequency of sports participation) and the outcome (diagnosed health problems) were based on participant responses to the 
survey, which may have introduced some bias. As frequency is only one component of the total volume of activity, future studies should extend assessments to include measures of duration and intensity. Although the recall period of 12 months allowed for consideration of the seasonal nature of some activities like swimming, this may have introduced recall bias. Participants in any of the SRAs that were found to be associated with health outcomes (e.g. running and resistance training) may also have engaged in other SRAs (e.g. cycling or tennis). Moreover, our list of recreational activities did not include walking, which is the most common activity among older adults ${ }^{13,14}$. To account for differences in time spent in other physical activities, including walking for transport and recreation, all of which are captured in the Active Australia survey, we adjusted our analyses for total physical activity. After this adjustment the risk estimates were largely unchanged. While there was a 2-year lag between measurement of exposures and outcomes, reverse-causality cannot be ruled out. Even though important confounding variables were included in the analyses, there may have been residual confounding due to unmeasured variables, such as alcohol consumption, dietary habits, use of medicines and family history of hypertension or diabetes. More longitudinal cohort studies are needed to strengthen the evidence of these associations. Lastly, given the number of statistical tests, some associations may be due to chance. As our purpose was exploratory rather confirmatory, further studies are needed to ratify our findings.

\section{Perspective}

This study adds to our understanding of what is currently known about the relationships between participation in sport and recreational activities with health in mid-age. The findings show positive associations between at least weekly participation in a wide range of SRAs, including group activities [such as team sports, tennis and exercise classes] and those which involve muscle strengthening [eg resistance training, yoga/taichi], as well as the more 'traditional' aerobic activities [running and cycling], with three important long term health conditions (hypertension, diabetes and obesity). As our 'baby boomer' population is now at a life stage characterised by marked increases in the prevalence of these (and other) health risks, our findings support current efforts by government and non-government organisations to create opportunities for more widespread access to, and continuing participation in, the types of activities that are preferred by mid-age adults. Future studies should assess whether continued participation in these activities into older age is associated with decreased pharmaceutical, social and medical costs of managing hypertension, diabetes and obesity in the long term. 


\section{Acknowledgements}

We acknowledge our HABITAT CoCIs and project staff for assistance with survey development, project management, data collection, coding and cleaning, and data management.

\section{Funding}

The HABITAT Study was funded by the National Health and Medical Research Council (NHMRC) (IDs 497236, 339718, 1047453). Brisbane City Council provided additional funding support and specific geographical data. GIM is supported by a Development Fellowship from The University of Queensland. The funding bodies did not contribute to the design of the study or to collection, analysis, and interpretation of data or writing the manuscript.

\section{Competing interests}

The authors declare no conflict of interest.

\section{Data availability statement}

There are no linked research data sets for this submission. The data used are confidential.

\section{References}

1. Piercy KL, Troiano RP, Ballard RM, Carlson SA, Fulton JE, Galuska DA, et al. The Physical Activity Guidelines for Americans. JAMA. 2018;320(19):2020-8.

2. Global action plan on physical activity 2018-2030: more active people for a healthier world. Geneva: World Health Organization; 2018. Licence: CC BY-NC-SA 3.0 IGO.

3. Sallis JF, Bull F, Guthold R, Heath GW, Inoue S, Kelly P, et al. Progress in physical activity over the Olympic quadrennium. Lancet. 2016;388(10051):1325-36.

4. Ding D, Lawson KD, Kolbe-Alexander TL, Finkelstein EA, Katzmarzyk PT, van Mechelen W, et al. The economic burden of physical inactivity: a global analysis of major noncommunicable diseases. Lancet. 2016;388(10051):1311-24.

5. Khan KM, Thompson AM, Blair SN, Sallis JF, Powell KE, Bull FC, et al. Sport and exercise as contributors to the health of nations. Lancet. 2012;380(9836):59-64.

6. Sport 2030. In: Departmanet of Health Commonwealth of Australia, 2018. 
7. Oja P, Titze S, Kokko S, Kujala UM, Heinonen A, Kelly P, et al. Health benefits of different sport disciplines for adults: systematic review of observational and intervention studies with meta-analysis. Br J Sports Med. 2015;49(7):434-40.

8. Oja P, Kelly P, Pedisic Z, Titze S, Bauman A, Foster C, et al. Associations of specific types of sports and exercise with all-cause and cardiovascular-disease mortality: a cohort study of 80306 British adults. Br J Sports Med. 2017;51(10):812-7.

9. Dash SR, Hoare E, Varsamis P, Jennings GLR, Kingwell BA. Sex-Specific Lifestyle and Biomedical Risk Factors for Chronic Disease among Early-Middle, Middle and Older Aged Australian Adults. Int J Environ Res Public Health. 2019;16(2).

10. Burton NW, Haynes M, Wilson LA, Giles-Corti B, Oldenburg BF, Brown WJ, et al. HABITAT: A longitudinal multilevel study of physical activity change in mid-aged adults. BMC Public Health. 2009;9:76.

11. Brown WJ, Trost SG, Bauman A, Mummery K, Owen N. Test-retest reliability of four physical activity measures used in population surveys. J Sci Med Sport. 2004;7(2):205-15.

12. Brown WJ, Bauman AE, Bull F, Burton NW. Development of evidence-based physical activity recommendations for adults (18-64 years). Report prepared for the Australian Government Department of Health, August 2012.

http://www.health.gov.au/internet/main/publishing.nsf/Content/health-pubhlth-strateg-phys-actguidelines/\$File/DEB-PAR-Adults-18-64years.pdf.

13. Australian Institute of Health and Welfare. Physical activity across the life stages. Cat. no. PHE 225. Canberra: AIHW; 2018.

14. National Centre for Cultural and Recreation Studies Australian Bureau of Statistics. Participation in Sport ad Physical Recreation, Australia. 2011-12 report. Australian Sports Commission, Canberra: Australian Bureau of Statistics; 2013.

15. Hinds A, Gordon J, Crouch L. Department of National Parks, Sport and Racing. Queensland Sport, Exercise and Recreation Survey Adults (QSERSA). https://www.qld.gov.au/_data/assets/pdf_file/0022/8671/active-qld-adult-participationsurvey.pdf. 2016.

16. Burton NW, Khan A, Brown WJ. How, where and with whom? Physical activity context preferences of three adult groups at risk of inactivity. Br J Sports Med. 2012;46(16):1125-31. 
17. Salmon J, Owen N, Crawford D, Bauman A, Sallis JF. Physical activity and sedentary behavior: a population-based study of barriers, enjoyment, and preference. Health Psychol. 2003;22(2):178-88.

18. van Uffelen JGZ, Khan A, Burton NW. Gender differences in physical activity motivators and context preferences: a population-based study in people in their sixties. BMC Public Health. 2017;17(1):624.

19. Jenkin CR, Eime RM, Westerbeek H, O'Sullivan G, van Uffelen JGZ. Sport and ageing: a systematic review of the determinants and trends of participation in sport for older adults. BMC Public Health. 2017;17(1):976.

20. Austrlian Bureau of Statistics 2011 [Available from:

http:/quickstats.censusdata.abs.gov.au/census_services/getproduct/census/2011/quickstat/3GBRI? opendocument.

21. Australian Institute of Health and Welfare 2018. Australia's health 2018. Australia's health series no. 16. AUS 221. Canberra: AIHW.

22. Lee DC, Pate RR, Lavie CJ, Sui X, Church TS, Blair SN. Leisure-time running reduces allcause and cardiovascular mortality risk. J Am Coll Cardiol. 2014;64(5):472-81.

23. Schnohr P, Marott JL, Lange P, Jensen GB. Longevity in male and female joggers: the Copenhagen City Heart Study. Am J Epidemiol. 2013;177(7):683-9.

24. Pedisic Z, Shrestha N, Kovalchik S, et al. Is running associated with a lower risk of allcause, cardiovascular and cancer mortality, and is the more the better? A systematic review and meta-analysis [published online ahead of print, 2019 Nov 4]. Br J Sports Med. 2019.

25. Littman AJ, Kristal AR, White E. Effects of physical activity intensity, frequency, and activity type on 10-y weight change in middle-aged men and women. Int J Obes (Lond). 2005;29(5):524-33.

26. Kelly P, Kahlmeier S, Gotschi T, Orsini N, Richards J, Roberts N, et al. Systematic review and meta-analysis of reduction in all-cause mortality from walking and cycling and shape of dose response relationship. Int J Behav Nutr Phys Act. 2014;11:132.

27. Murray AD, Daines L, Archibald D, Hawkes RA, Schiphorst C, Kelly P, et al. The relationships between golf and health: a scoping review. Br J Sports Med. 2017;51(1):12-9. 28. Luscombe J, Murray AD, Jenkins E, Archibald D. A rapid review to identify physical activity accrued while playing golf. BMJ Open. 2017;7(11):e018993. 
29. Parkkari J, Natri A, Kannus P, Manttari A, Laukkanen R, Haapasalo H, et al. A controlled trial of the health benefits of regular walking on a golf course. Am J Med. 2000;109(2):102-8.

30. Arem H, Moore SC, Patel A, Hartge P, Berrington de Gonzalez A, Visvanathan K, et al. Leisure time physical activity and mortality: a detailed pooled analysis of the dose-response relationship. JAMA Intern Med. 2015;175(6):959-67.

31. Saint-Maurice PF, Coughlan D, Kelly SP, Keadle SK, Cook MB, Carlson SA, et al. Association of Leisure-Time Physical Activity Across the Adult Life Course With All-Cause and Cause-Specific Mortality. JAMA Netw Open. 2019;2(3):e190355. 
Table 1: Description of the sample at baseline (2007) in terms of sociodemographic and chronic health condition variables. Brisbane, Australia, 2007. $(\mathbf{N}=\mathbf{8 , 7 8 4})^{\text {a }}$

\begin{tabular}{|c|c|c|c|c|c|c|c|c|}
\hline \multirow{3}{*}{ Variable } & \multirow{2}{*}{\multicolumn{2}{|c|}{ Description of the sample }} & \multicolumn{6}{|c|}{ Prevalence of long term health conditions at baseline } \\
\hline & & & \multicolumn{2}{|c|}{ Hypertension } & \multicolumn{2}{|c|}{ Diabetes } & \multicolumn{2}{|l|}{ Obesity } \\
\hline & $\mathrm{N}$ & $\%$ & $\%(95 \% \mathrm{CI})$ & $\mathrm{p}^{\mathrm{b}}$ & $\%(95 \% \mathrm{CI})$ & $\mathrm{p}^{\mathrm{b}}$ & $\%(95 \% \mathrm{CI})$ & $\mathrm{p}^{\mathrm{b}}$ \\
\hline Gender & & & & 0.002 & & $<0.001$ & & 0.097 \\
\hline Men & 3,774 & 43.0 & $23.1(21.7-24.5)$ & & $6.2(5.4-7.0)$ & & $21.9(20.6-23.3)$ & \\
\hline Women & 5,010 & 57.0 & $20.3(19.2-21.4)$ & & $4.1(3.6-4.7)$ & & $20.5(19.3-21.6)$ & \\
\hline Age (years) & & & & $<0.001$ & & $<0.001$ & & 0.843 \\
\hline$<45$ & 1,915 & 21.8 & $10.4(9.1-11.9)$ & & $2.2(1.6-3.0)$ & & $20.9(19.1-22.9)$ & \\
\hline $45-59$ & 5,409 & 61.6 & $21.3(20.2-22.4)$ & & $4.7(4.2-5.3)$ & & $21.3(20.2-22.4)$ & \\
\hline$\geq 60$ & 1,460 & 16.6 & $37.1(34.6-39.7)$ & & $10.1(8.5-11.8)$ & & $20.6(18.5-22.8)$ & \\
\hline Highest education degree & & & & $<0.001$ & & 0.001 & & $<0.001$ \\
\hline Bachelor degree or higher & 2,861 & 32.7 & $17.8(16.4-19.2)$ & & $4.0(3.3-4.7)$ & & $16.7(15.4-18.2)$ & \\
\hline Diploma/Associate degree & 1,020 & 11.7 & $20.5(18.0-23.1)$ & & $4.1(3.0-5.5)$ & & $18.7(16.3-21.3)$ & \\
\hline Certificated (trade/business) & 1,546 & 17.6 & $20.2(18.2-22.3)$ & & $5.4(4.3-6.6)$ & & $22.7(20.6-24.9)$ & \\
\hline Year 12 or less & 3,331 & 38.0 & $25.6(24.1-27.2)$ & & $6.1(5.3-7.0)$ & & $24.9(23.4-26.5)$ & \\
\hline Annual family income (AU) & & & & $<0.001$ & & $<0.001$ & & $<0.001$ \\
\hline$\$ 93,600$ or more & 2,779 & 36.6 & $17.2(15.8-18.7)$ & & $3.0(2.4-3.7)$ & & $18.2(16.7-19.7)$ & \\
\hline$\$ 52,000-93,599 /$ year & 2,456 & 32.3 & $20.2(18.6-21.9)$ & & $4.2(3.4-5.1)$ & & $21.7(20.1-23.4)$ & \\
\hline$\$ 20,800-51,999 /$ year & 1,801 & 23.7 & $26.3(24.2-28.4)$ & & $7.1(5.9-8.4)$ & & $23.6(21.7-25.7)$ & \\
\hline
\end{tabular}




\begin{tabular}{|c|c|c|c|c|c|c|c|c|}
\hline$<\$ 20,799 /$ year & 565 & 7.4 & $36.6(32.5-40.8)$ & & $12.5(9.7-15.6)$ & & $29.6(25.8-33.7)$ & \\
\hline Living arrangements & & & & $<0.001$ & & $<0.001$ & & $<0.001$ \\
\hline Single/living with children & 2,497 & 28.6 & $24.0(22.3-25.8)$ & & $6.4(5.5-7.4)$ & & $24.4(22.7-26.2)$ & \\
\hline Married/de facto & 6,229 & 71.4 & $20.5(19.5-21.5)$ & & $4.5(4.0-5.0)$ & & $19.7(18.7-20.7)$ & \\
\hline Smoking status & & & & 0.026 & & 0.012 & & 0.450 \\
\hline Never & 4,502 & 51.7 & $20.5(19.3-21.7)$ & & $4.5(3.9-5.1)$ & & $20.9(19.7-22.2)$ & \\
\hline Ex-smoker & 2,946 & 33.8 & $23.2(21.7-24.8)$ & & $5.3(4.5-6.2)$ & & $21.5(20.0-23.1)$ & \\
\hline Occasionally & 251 & 2.9 & $18.6(13.9-24.0)$ & & $4.9(2.5-8.3)$ & & $17.3(12.7-22.6)$ & \\
\hline Daily & 1,008 & 11.6 & $21.3(18.8-24.0)$ & & $7.0(5.4-8.7)$ & & $21.6(19.0-24.3)$ & \\
\hline Physical activity (MET.min/week) & & & & 0.041 & & 0.035 & & $<0.001$ \\
\hline$<33.3$ & 1,168 & 13.6 & 24.4 (21.9-27.0) & & $6.6(5.2-8.2)$ & & $30.7(28.0-33.5)$ & \\
\hline$<33.3-499.9$ & 2,307 & 26.9 & $21.9(20.2-23.7)$ & & $5.1(4.2-6.1)$ & & $24.7(22.9-26.6)$ & \\
\hline $500-1999.9$ & 3,404 & 39.8 & $20.5(19.1-21.9)$ & & $4.4(3.7-5.1)$ & & $18.7(17.4-20.1)$ & \\
\hline$\geq 2000$ & 1,684 & 19.7 & $20.9(19.0-22.9)$ & & $5.1(4.0-6.2)$ & & $15.2(13.5-17.0)$ & \\
\hline
\end{tabular}

a Analytical sample included only participants who responded at least two surveys; ${ }^{b}$ chi-square for heterogeneity

This article is protected by copyright. All rights reserved 
Table 2: Frequency of sports and recreational activities according to gender and age groups at baseline. Brisbane, Australia, 2007. $\mathrm{N}=8,784^{a}$

\begin{tabular}{|c|c|c|c|c|c|c|}
\hline \multirow{3}{*}{ Frequency in last 12 months } & $\begin{array}{c}\text { Total } \\
(\mathrm{n}=8,784 \\
)\end{array}$ & $\begin{array}{c}\text { Men } \\
(n=3,774\end{array}$ & $\begin{array}{l}\text { Women } \\
(n=5,010\end{array}$ & $\begin{array}{l}<45 \text { years } \\
(n=1,915\end{array}$ & $\begin{array}{c}45-59 \\
\text { years } \\
(n=5,409\end{array}$ & $\begin{array}{c}\geq 60 \text { years } \\
(n=1,460 \\
)\end{array}$ \\
\hline & & ) & ） & ) & ) & \\
\hline & $\mathrm{N}(\%)$ & $\%$ & $\%$ & $\%$ & $\%$ & $\%$ \\
\hline
\end{tabular}

Running or jogging

Never

5,792

(67.3)

60.1

72.7

53.1

68.2

82.7

Some

1,452

(16.9)

21.2

23.6

16.5

9.2

1,366

Once/more week

(15.8)

18.8

13.6

23.2

15.3

8.2

Cycling

Never

$$
5,715
$$

(66.3)

$\begin{array}{ll}57.7 & 72.8\end{array}$

49.1

68.2

82.0

1,900

Some

(22.0)

27.1

18.2

35.4

20.3

10.7

1,008

Once/more week

(11.7)

15.2

15.5

11.5

7.3

Swimming

Never

4,786

(55.4)

$54.1 \quad 56.3$

41.1

57.0

68.1

Some

2,945

$36.4 \quad 32.3$

45.3

33.3

21.9

913

Once/more week

9.5

11.4

13.6

9.7

10.0

Golf

Never

7,225

72.0

92.4

78.6

84.2

88.0

(83.6)

Some

1,119

(13.0)

22.8

19.6

12.3

6.5

Once/more week

297 (3.4)

5.2

2.1

1.8

3.5 


\section{Lawn bowls}

Never

Some

Once/more week

Tennis

Never

Some

Once/more week

Team sports

Never

8,009

(92.6)

273 (3.2)

89.3

13.6

(11.9)

307 (3.7)

3.3

3.7

5.3

0.9

85.7

77.1

85.6

90.6

19.7

10.9

4.9

3.2

3.5

3.4

365 (4.2)

5.2

5.5

1.6

3.2

Once/more week

Home-based exercises

Never

4,821

(55.8)

$61.3 \quad 51.9$

1,549

Some

Once/more week

Exercise class

Never

Some

Once/more week

Resistances training

Never

Some
5,939

(68.9)

68.0

986

$\begin{array}{lll}6,952 & & \\ (81.9) & & 91.3\end{array}$

$\begin{array}{lll}581(6.8) & 3.8 & 9.0\end{array}$

1,053

(12.3)

$4.9 \quad 17.8$

$8.9 \quad 6.5$

4.8

$12.1 \quad 12.4$

12.1

(11.5)

69.6

59.8

69.3

79.6

$16.7 \quad 11.0$

6.2

10.3 


\begin{tabular}{lcccccc}
\hline Once/more week & $\begin{array}{c}1,691 \\
(19.6)\end{array}$ & 19.0 & 20.1 & 23.5 & 19.7 & 14.2 \\
Yoga, Pilates, tai chi or qi & & & & & & \\
gong & & & & & & \\
Never & 7,204 & & & & & \\
Some & $(83.2)$ & 93.0 & 75.8 & & 82.5 & \\
Once/more week & $705(8.1)$ & 3.7 & 11.5 & 10.4 & 8.2 & 4.9 \\
\hline
\end{tabular}

a Analytical sample included only participants who responded at least two surveys

Table 3: Association between sports and recreational activities with incident hypertension. Brisbane, Australia 2007-2013.

\begin{tabular}{lcc}
\hline Frequency in last 12 months & Model 1 & Model 2 \\
& OR $(95 \% \mathrm{CI})$ & OR $(95 \% \mathrm{CI})$
\end{tabular}

Running or jogging

$\begin{array}{lcc}\text { Never } & 1.00 & 1.00 \\ \text { Some } & 0.77(0.67-0.89) & 0.78(0.67-0.90) \\ \text { Once/more week } & 0.68(0.57-0.80) & 0.71(0.60-0.85) \\ \text { ycling } & & \\ \text { Never } & 1.00 & 1.00 \\ \text { Some } & 0.90(0.79-1.04) & 0.91(0.79-1.04) \\ \text { Once/more week } & 0.89(0.74-1.07) & 0.93(0.76-1.13)\end{array}$

Swimming

Never

1.00

1.00

Some

$0.98(0.88-1.10)$

$0.99(0.89-1.12)$

Once/more week

$1.01(0.84-1.22)$

$1.05(0.86-1.27)$

Golf

Never

1.00

1.00

Some

$0.87(0.72-1.04)$

$0.86(0.72-1.04)$

Once/more week

$1.26(0.92-1.72)$

$1.37(1.00-1.89)$

Lawn bowls

Never

1.00

1.00

Some

$1.03(0.83-1.29)$

$1.03(0.82-1.30)$

Once/more week

$0.83(0.46-1.49)$

$0.94(0.54-1.62)$ 
Tennis

Never

Some

Once/more week

Team sports

Never

Some

Once/more week

Home-based exercises

Never

Some

Once/more week

Exercise class

Never

Some

Once/more week

Resistance training

Never

Some

Once/more week
1.00

$0.94(0.79-1.11)$

$0.68(0.48-0.97)$

1.00

$0.94(0.69-1.28)$

$0.73(0.55-0.98)$

1.00

$0.88(0.76-1.02)$

$0.93(0.83-1.05)$

1.00

$1.06(0.87-1.28)$

$0.83(0.70-0.97)$

1.00

$0.85(0.73-1.00)$

$0.77(0.67-0.89)$
1.00

$0.97(0.81-1.15)$

$0.72(0.50-1.03)$

1.00

$0.95(0.69-1.32)$

$0.74(0.55-1.02)$

$0.89(0.77-1.02)$

$0.95(0.85-1.07)$

1.00

$1.06(0.87-1.30)$

$0.85(0.72-1.01)$

1.00

$0.87(0.75-1.03)$

$0.81(0.69-0.94)$

Yoga, Pilates, tai chi or qi gong

Never

1.00

1.00

Some

$0.98(0.82-1.17)$

$0.98(0.82-1.18)$

Once/more week

$0.84(0.70-1.01)$

Model 1: sex, age, education, annual income, living arrangements, cigarette smoking status; Model 2: Model 1+ physical activity in MET.min/week.

Table 4: Association between sports and recreational activities with incident diabetes. Brisbane, Australia 2007-2013.

Frequency in last 12 months

Model $1 \quad$ Model 2

OR $(95 \% \mathrm{CI})$

OR $(95 \% \mathrm{CI})$

\section{Running or jogging}

Never

1.00

1.00

Some

$0.72(0.53-0.97)$

$0.77(0.57-1.04)$

This article is protected by copyright. All rights reserved 
Cycling

Never

1.00

1.00

Some

$0.67(0.50-0.89)$

$0.69(0.52-0.92)$

Once/more week

$0.60(0.42-0.86)$

$0.62(0.42-0.92)$

Swimming

Never

1.00

1.00

Some

$0.77(0.61-0.97)$

$0.83(0.66-1.05)$

Once/more week

$0.77(0.50-1.17)$

$0.86(0.57-1.30)$

Golf

Never

1.00

1.00

Some

$0.79(0.58-1.08)$

$0.80(0.59-1.09)$

Once/more week

$0.83(0.45-1.55)$

$0.98(0.52-1.87)$

Lawn bowls

Never

1.00

1.00

Some

$0.57(0.32-1.01)$

$0.57(0.32-1.03)$

Once/more week

$1.03(0.52-2.04)$

$1.18(0.58-2.37)$

Tennis

Never

1.00

1.00

Some

$0.63(0.44-0.91)$

$0.70(0.49-0.99)$

Once/more week

$0.82(0.47-1.42)$

$0.97(0.55-1.69)$

Team sports

Never

1.00

1.00

Some

$1.56(0.90-2.71)$

$1.66(0.95-2.90)$

Once/more week

$1.35(0.91-2.03)$

$1.48(0.96-2.27)$

Home-based exercises

Never

1.00

1.00

Some

$0.86(0.67-1.10)$

$0.82(0.63-1.06)$

Once/more week

$0.81(0.64-1.02)$

$0.83(0.65-1.05)$

Exercise class

Never

1.00

1.00

Some

$1.21(0.84-1.73)$

$1.25(0.86-1.82)$

Once/more week

$0.90(0.64-1.26)$

$1.03(0.73-1.45)$

Resistance training 


\begin{tabular}{lcc}
\hline Never & 1.00 & 1.00 \\
Some & $0.77(0.57-1.04)$ & $0.72(0.53-0.98)$ \\
Once/more week & $0.66(0.49-0.89)$ & $0.70(0.51-0.95)$ \\
Yoga, Pilates, tai chi or qi gong & & 1.00 \\
Never & 1.00 & $0.76(0.50-1.14)$ \\
Some & $0.76(0.52-1.12)$ & $0.75(0.52-1.09)$ \\
Once/more week & $0.68(0.47-0.99)$ & \\
\hline
\end{tabular}

Model 1: sex, age, education, annual income, living arrangements, cigarette smoking status; Model 2: Model 1 + physical activity in MET.min/week. 
Table 5: Association between sports and recreational activities with incident obesity. Brisbane, Australia 2007-2013.

- Model 1 $\quad$ Model 2

Frequency in last 12 months

$\begin{array}{cc}\text { Model } 1 & \text { Model } 2 \\ \text { OR }(95 \% \mathrm{CI}) & \text { OR }(95 \% \mathrm{CI})\end{array}$

Running or jogging

Never

1.00

1.00

Some

$0.89(0.77-1.02)$

$0.89(0.77-1.03)$

Once/more week

$0.90(0.76-1.06)$

$0.89(0.75-1.06)$

Cycling

Never

1.00

1.00

Some

$0.91(0.79-1.04)$

$0.91(0.79-1.04)$

Once/more week

$0.72(0.60-0.87)$

$0.72(0.59-0.88)$

Swimming

Never

1.00

1.00

Some

$0.99(0.88-1.12)$

$0.99(0.87-1.12)$

Once/more week

$1.04(0.86-1.26)$

$1.06(0.87-1.29)$

Golf

Never

1.00

1.00

Some

$0.90(0.75-1.08)$

$0.90(0.74-1.09)$

Once/more week

$0.82(0.58-1.16)$

$0.84(0.58-1.21)$

Lawn bowls

Never

1.00

1.00

Some

$1.01(0.81-1.25)$

$1.00(0.80-1.25)$

Once/more week

$0.82(0.47-1.41)$

$0.75(0.41-1.36)$

Tennis

Never

$$
1.00
$$

1.00

Some

$0.74(0.61-0.90)$

$0.76(0.62-0.93)$

Once/more week

$0.61(0.42-0.89)$

$0.65(0.45-0.95)$

Team sports

Never

1.00

1.00

Some

$1.01(0.74-1.37)$

$1.00(0.73-1.37)$

Once/more week

$0.94(0.69-1.26)$

$0.93(0.67-1.27)$

Home-based exercises

Never

1.00

1.00

This article is protected by copyright. All rights reserved 


\begin{tabular}{lcc}
\hline Some & $1.05(0.92-1.21)$ & $1.06(0.92-1.21)$ \\
Once/more week & $0.88(0.78-0.99)$ & $0.88(0.77-1.00)$ \\
Exercise class & & 1.00 \\
Never & $0.87(0.70-1.08)$ & $0.89(0.71-1.11)$ \\
Some & $0.94(0.78-1.12)$ & $0.97(0.80-1.17)$ \\
Once/more week & & 1.00 \\
Resistance trainings & 1.00 & $0.93(0.78-1.10)$ \\
Never & $0.91(0.77-1.08)$ & $0.83(0.71-0.98)$ \\
Some & $0.81(0.70-0.95)$ & 1.00 \\
Once/more week & & $0.94(0.77-1.15)$ \\
Yoga, Pilates, tai chi or qi gong & 1.00 & $0.77(0.62-0.95)$ \\
Never & $0.93(0.77-1.14)$ & $0.75(0.61-0.92)$ \\
Some & & \\
Once/more week & & \\
\hline
\end{tabular}

Model 1: sex, age, education, annual income, living arrangements, cigarette smoking status; Model 2: Model 1+ physical activity in MET.min/week. 